\title{
HDAC-mediated control of ERK- and PI3K-dependent TGF- $\beta$-induced extracellular matrix-regulating genes
}

\author{
Matt J. Barter a , Leon Pybus ${ }^{a}$, Gary J. Litherland a, Andrew D. Rowan a , Ian M. Clark ${ }^{\mathrm{b}}$, Dylan R. Edwards ${ }^{\mathrm{b}}$, \\ Tim E. Cawston ${ }^{\text {a }}$, David A. Young ${ }^{\text {a,* }}$ \\ a Institute of Cellular Medicine, Newcastle University, Newcastle upon Tyne, NE2 4HH, UK \\ b School of Biological Sciences, University of East Anglia, Norwich, NR4 7TJ, UK
}

\section{A R T I C L E I N F O}

\section{Article history:}

Received 27 January 2010

Received in revised form 14 April 2010

Accepted 3 May 2010

\section{Keywords:}

Histone deacetylases

HDAC3

TGF- $\beta$

Signalling

ERK

PI3K

ADAM12

TIMP-1

\begin{abstract}
A B S T R A C T
Histone deacetylases (HDACs) regulate the acetylation of histones in the control of gene expression. Many non-histone proteins are also targeted for acetylation, including TGF- $\beta$ signalling pathway components such as Smad2, Smad3 and Smad7. Our studies in mouse C3H10T1/2 fibroblasts suggested that a number of TGF$\beta$-induced genes that regulate matrix turnover are selectively regulated by HDACs. Blockade of HDAC activity with trichostatin A (TSA) abrogated the induction of a disintegrin and metalloproteinase 12 (Adam12) and tissue inhibitor of metalloproteinases-1 (Timp-1) genes by TGF- $\beta$, whereas plasminogen activator inhibitor- 1 (Pai-1) expression was unaffected. Analysis of the activation of cell signalling pathways demonstrated that TGF- $\beta$ induced robust ERK and PI3K activation with delayed kinetics compared to the phosphorylation of Smads. The TGF- $\beta$ induction of Adam12 and Timp-1 was dependent on such non-Smad signalling pathways and, importantly, HDAC inhibitors completely blocked their activation without affecting Smad signalling. Analysis of TGF- $\beta$-induced Adam 12 and Timp- 1 expression and ERK/PI3K signalling in the presence of semiselective HDAC inhibitors valproic acid, MS-275 and apicidin implicated a role for class I HDACs. Furthermore, depletion of HDAC3 by RNA interference significantly down-regulated TGF- $\beta$-induced Adam 12 and Timp-1 expression without modulating Pai-1 expression. Correlating with the effect of HDAC inhibitors, depletion of HDAC3 also blocked the activation of ERK and PI3K by TGF- $\beta$. Collectively, these data confirm that HDACs, and in particular HDAC3, are required for activation of the ERK and PI3K signalling pathways by TGF- $\beta$ and for the subsequent gene induction dependent on these signalling pathways.
\end{abstract}

(c) 2010 Elsevier B.V. All rights reserved.

\section{Introduction}

TGF- $\beta$ is a key regulator of extracellular matrix (ECM) formation and remodelling. To perform this role TGF- $\beta$ induces the expression of integral ECM proteins, proteases, and their inhibitors, such as the tissue inhibitors of metalloproteinases (TIMPs). Regulation of ECM breakdown and remodelling is critical in development and morphogenesis, as well as in physiological and pathological processes such as fibrosis, wound healing, tumour metastasis and joint destruction in arthritis.

Abbreviations: HDAC, Histone deacetylase; ERK, Extracellular signal-regulated kinase; PI3K, Phosphatidylinositol 3-kinase; TGF- $\beta$, Transforming growth factor- $\beta$; ECM, Extracellular matrix; TSA, Trichostatin A; ADAM12, A disintegrin and metalloproteinase 12; TIMP-1, Tissue inhibitor of metalloproteinases-1; PAI-1, Plasminogen activator inhibitor-1; MAPK, Mitogen-activated protein kinase; JNK, c-Jun N-terminal kinase; AP-1, Activator Protein-1; VPA, Valproic acid.

* Corresponding author. Institute of Cellular Medicine, 4th Floor Cookson Building Medical School, Newcastle University, Newcastle upon Tyne, NE2 4HH, UK. Tel.: + 44 191 2223850; fax: + 441912225455 .

E-mail address: d.a.young@ncl.ac.uk (D.A. Young).
TGF- $\beta$ signalling in mammalian cells is mediated through an interaction of type I and type II TGF- $\beta$ receptors (T $\beta R$ ), which upon ligand binding propagate further signalling to intracellular targets via their receptor kinase activity. Classically, TGF- $\beta$ receptor activation leads to phosphorylation of the R-Smads, Smad2 and Smad3. These recruit the Co-Smad (Smad4), translocate to the nucleus and, by a direct binding to cognate Smad-binding elements (SBEs), regulate the transcription of TGF- $\beta$ target genes. The inhibitor Smad7 is induced in response to TGF- $\beta$ to negatively regulate Smad signalling (Shi and Massague, 2003). TGF- $\beta$ can also signal through other pathways such as the mitogen-activated protein kinase (MAPK) and phosphatidylinositol 3-kinase (PI3K) pathways (Derynck and Zhang, 2003). This can occur rapidly via association of upstream activators of MAPK signalling with the TBR, for instance the activation of Ras by Shc association with TBRI (Lee et al., 2007), or with more delayed kinetics requiring intermediate Smad-dependent and -independent transcription responses and/or autocrine growth factor release (Cho et al., 2007; Horowitz et al., 2004).

The packaging of eukaryotic DNA into nucleosomes also regulates gene expression. Nucleosomes are generally considered repressive to transcription, but one mechanism to overcome this inhibition is 
through the enzymatic modification of histones via acetylation (Kouzarides, 2007; Li et al., 2007). Acetylation is mediated by histone acetyltransferases (HATs) and occurs on specific lysine residues on the $\mathrm{N}$-terminal tails of histones $\mathrm{H} 3$ and $\mathrm{H} 4$, which is proposed to loosen the histone:DNA structure allowing access of the transcriptional machinery and binding of acetyl groups by proteins containing bromo-domains (Clayton et al., 2006). Eleven histone deacetylases (HDACs) have been characterised which remove these acetyl groups resulting in hypo-acetylation (de Ruijter et al., 2003; Gregoretti et al., 2004). Numerous transcriptional activators/co-activators or repressors/co-repressors have been identified which have (or recruit) HAT or HDAC activity, respectively. Non-histone substrates of HATs (and subsequently HDACs) have also been described which include, amongst others, numerous transcription factors and signalling pathway proteins (Glozak et al., 2005).

In theory, hyper-acetylation of histones associates with transcriptional activation, and the converse, hypo-acetylation of histones is associated with transcriptional repression. However, in large scale gene studies a significant number of genes are also down-regulated in the presence of HDAC inhibitors (Xu et al., 2007). In addition, global HDAC inhibition with trichostatin A (TSA), a non-selective general HDAC inhibitor, causes the repression of a subset of TGF- $\beta$-induced genes (Ghosh et al., 2007; Glenisson et al., 2007; Kuang et al., 2007; Rombouts et al., 2002) and suppresses TGF- $\beta$-induced epithelial-tomesenchymal transition in human renal epithelial cells (Yoshikawa et al., 2007). We previously reported that HDAC inhibitors also repressed TGF-ß-induced Timp-1 expression (Young et al., 2005), providing insight into the mechanisms underlying Timp-1 expression and offering the opportunity of modulating Timp-1 expression in pathology. However, the mechanisms of HDAC inhibitor-mediated repression of TGF- $\beta$-induced gene expression remain unclear.

Here we use Timp- 1 and another TGF- $\beta$-induced gene, the membrane-bound protease Adam12, both of which are Smaddependent but exhibit differences in the non-Smad signalling elements of their induction, to show that HDAC inhibitors repress the induction of these genes via regulation of non-Smad signalling pathways such as the ERK and PI3K pathways. TGF- $\beta$-induced Pai-1 expression is also presented as a control gene unaffected by HDAC inhibitors. RNA interference (RNAi)-mediated depletion demonstrated that HDAC3 mediates the TGF- $\beta$-induced expression of Adam12 and Timp-1, via controlling the level of ERK and PI3K activation. Overall our data show that HDACs are critically important for gene induction by TGF- $\beta$ via the regulation of MAPK and PI3K activation.

\section{Results}

\subsection{Histone deacetylases regulate a subset of TGF- $\beta$-induced genes}

We used real-time RT-PCR to measure the time-course of Adam12, Timp-1 and Pai-1 induction by TGF- $\beta$ in the murine pluripotent mesenchymal $\mathrm{C} 3 \mathrm{H} 10 \mathrm{~T} 1 / 2$ cell line, which has been widely used to study responses to the TGF- $\beta$ family of growth factors (Denker et al., 1995; Wang et al., 1993; Young et al., 2005). Adam12 and Timp-1 induction was a late event, maximal at $8 \mathrm{~h}$ (Fig. 1A), and subsequent experiments were performed at this time-point. We confirmed the role of Smad signalling in the TGF- $\beta$ induction of Adam 12 and Timp-1 in comparison with Pai-1 by siRNA depletion of both the R-Smads (Smad2 and Smad3) and the co-Smad, Smad4. Both Adam12 and Timp- 1 inductions by TGF- $\beta$ were significantly reduced when Smad2, Smad3 or Smad4 were depleted (Fig. 1B). Depletion of Smad RNA levels was $>80 \%$ as measured by real-time RT-PCR while immunoblotting for Smad 2 and Smad4 demonstrated an almost complete loss of protein (Supp. Fig. 1). Previously, we reported that the HDAC inhibitor TSA could prevent the induction of Timp- 1 by TGF- $\beta$ in murine C3H10T1/2 and swiss-3T3 fibroblasts, implicating a role for HDACs in Timp-1 expression (Young et al., 2005). We confirmed this result and tested whether Adam12 and Pai-1 were also repressed by TSA (Fig. 1C). TSA had no effect on the induction of Pai-1 by TGF- $\beta$. By contrast, the TGF- $\beta$ induction of Adam12, as for Timp-1, was significantly blocked by treatment with TSA. TSA also reduced TGF$\beta$-induced ADAM12 expression in human dermal fibroblasts and SW1353 chondrosarcoma cells (Supp. Fig. 2).

\subsection{HDAC inhibitors do not significantly affect Smad signalling}

The induction of Adam 12 and Timp- 1 by TGF- $\beta$ is dependent on Smad signalling. To establish whether the inhibition of TGF- $\beta$-induced gene expression by HDAC inhibitors was mediated by modulation of Smad signalling we examined the phosphorylation status of Smad2. Treatment with TSA had no effect on the phosphorylation of Smad2 induced by TGF- $\beta$ (Fig. 2A). We then examined the effect of TSA on Smad2/3 nuclear translocation. Treatment with TSA had no significant effect on the accumulation of $\operatorname{Smad} 2 / 3$ in the nucleus after $1 \mathrm{~h}$ treatment with TGF- $\beta$ (Fig. 2B). To determine if TSA modulated Smaddependent transactivation we transfected cells with Smad3-dependent $\mathrm{CAGA}_{12}$-luc, or Smad3- and Activator Protein-1 (AP-1)-dependent 3TP-Lux reporter constructs (Dennler et al., 1998; Wrana et al., 1992). The activity of each promoter was induced by TGF- $\beta$ after $8 \mathrm{~h}$ (Fig. 2C). TSA had no effect on the transcriptional activity of the $\mathrm{CAGA}_{12}$-luc construct. By contrast, TSA partially reduced the transcriptional activity of the 3TP-Lux construct suggesting the AP-1responsive component was regulated by HDACs.

2.3. HDAC inhibitors regulate the activation of non-Smad signalling pathways by TGF- $\beta$

The relatively late induction of Timp- 1 and Adam 12 by TGF- $\beta$ implies the genes may not be a direct target of Smads. To determine which other non-Smad pathways regulated the induction of Adam12 and Timp- 1 by TGF- $\beta$ we used selective pathway inhibitors to the three MAPK pathways and PI3K/Akt. The induction of Adam12 was significantly dependent on all MAPK pathways and PI3K/Akt (Fig. 3A) confirming previous reports (Le Pabic et al., 2003, 2005), while Timp-1 required only MAPK signalling for maximal expression and was PI3Kindependent (Fig. 3A). We next characterised the effect of HDAC inhibitors on the activation of signalling pathways in C3H10T1/2 cells over a time-course of TGF- $\beta$ stimulation. TGF- $\beta$ activated each MAPK pathway and the PI3K (indicated by Akt phosphorylation) pathway, with the most marked activation after $4 \mathrm{~h}$ (Fig. 3B). This late signalling pathway activation appears critical to gene expression since the addition of the MEK inhibitor U0126 $2 \mathrm{~h}$ after TGF- $\beta$ stimulation also inhibited Adam12 and Timp-1 induction (Supp. Fig. 3).

Significantly, TSA blocked the late $(4 \mathrm{~h})$ activation of ERK and Akt (Fig. 3C), and Thr308 phosphorylation of Akt was also blocked (data not shown). TSA is a broad spectrum HDAC inhibitor, whereas a number of HDAC inhibitors, including VPA and MS-275 are proposed to be 'semi-selective' between HDAC family members (Khan et al., 2008). We found that VPA, but not MS-275, also blocked ERK and Akt activation. TSA also down-regulated JNK phosphorylation. We also examined the phosphorylation status of ERK and Akt substrates to demonstrate that this loss of activation has a functional effect. TSA and VPA both blocked the phosphorylation of the ERK substrate p90RSK and the Akt substrate GSK3 $\beta$ (Fig. 3C). We further examined the effect of HDAC inhibitors on the ERK pathway by studying the activation of upstream kinases. TSA and VPA (and to a lesser extent MS-275) also reduced the levels of c-Raf phosphorylation. We could not detect a significant increase in MEK phosphorylation in response to TGF- $\beta$ and therefore any effect of HDAC inhibitors (data not shown). TSA also reduced the TGF- $\beta$ induction of a MAPK-responsive reporter plasmid containing repeats recognised by serum response factor (SRF) (Fig. 3D), which is activated by ERK and JNK signalling pathways in response to TGF- $\beta$ (data not shown and (Whitmarsh et al., 1995)). We 

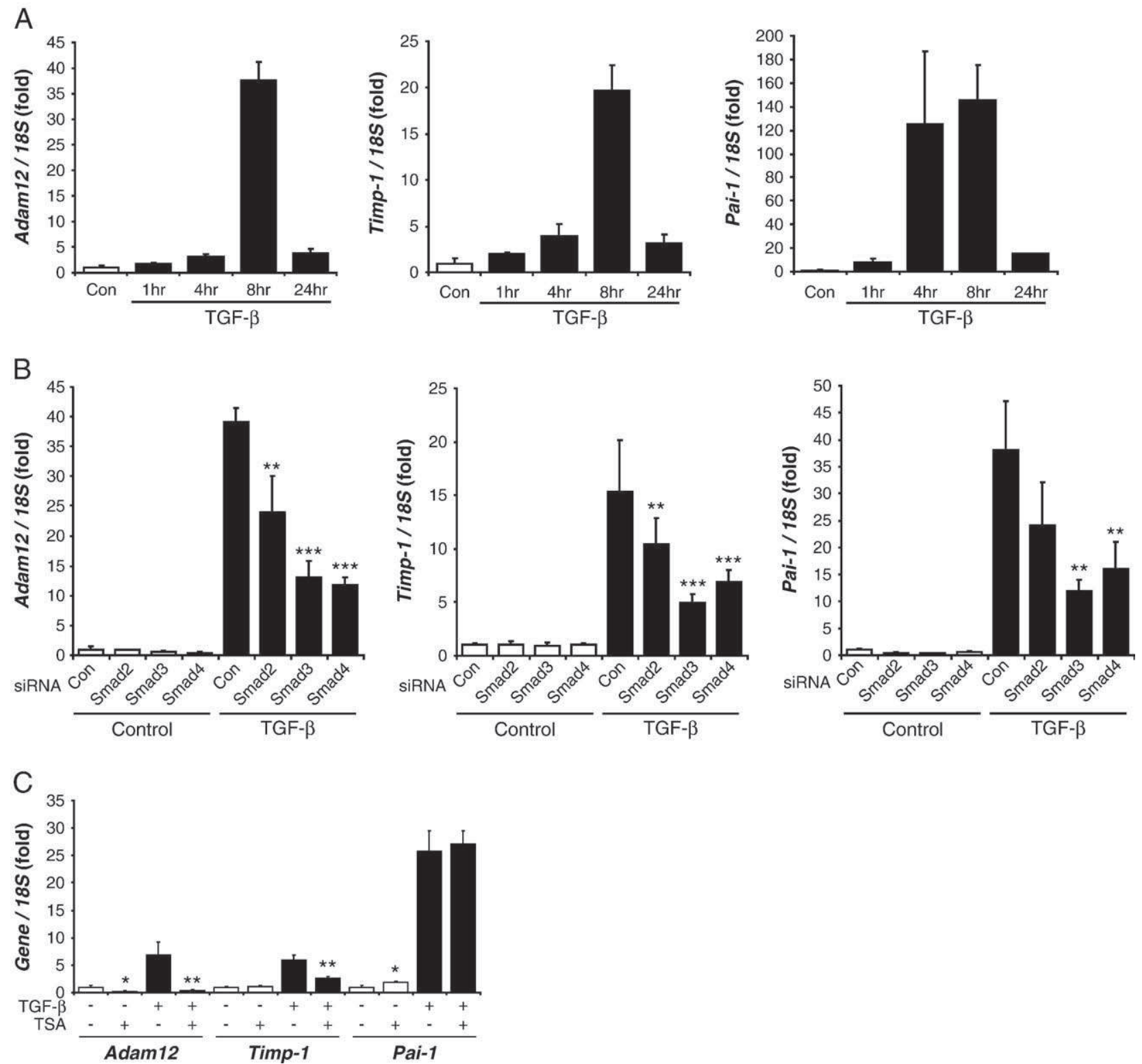

Fig. 1. TGF- $\beta$ induction of Adam 12 and Timp-1 is HDAC dependent. (A) C3H10T1/2 cells were stimulated with TGF- $\beta 1$ ( 2 ng/ml) for the indicated times and gene expression quantified by real-time RT-PCR from isolated RNA and normalised to the housekeeping gene $18 \mathrm{~S}(n=3)$. (B) Cells were transfected with Smad2, Smad3 or Smad4 siRNA or non-targeting control siRNA $(25 \mathrm{nM}$ ) for $24 \mathrm{~h}$. Cells were then serum-starved for $16 \mathrm{~h}$ and stimulated with TGF- $\beta 1(2 \mathrm{ng} / \mathrm{ml}$ ) for $8 \mathrm{~h}$ and gene expression quantified by real-time RT-PCR and normalised to $18 \mathrm{~S}$ ( $n=4$ ). (C) Cells were stimulated with TGF- $31(2 \mathrm{ng} / \mathrm{ml})$ for $8 \mathrm{~h}$ after treatment with TSA ( $100 \mathrm{ng} / \mathrm{ml})$ or DMSO $(0.01 \% \mathrm{v} / \mathrm{v})$. Total RNA was isolated and subjected to real-time RT-PCR for the indicated gene expression normalised to $18 \mathrm{~S}(n=3)$. Data are presented as fold induction relative to the basal expression and represent mean \pm S.D. $\left({ }^{*} p<0.01\right.$, ${ }^{* *} p<0.01$, $\left.{ }^{* * *} p<0.001\right)$. Data are representative of three independent experiments.

confirmed that TSA, VPA and MS-275 were all able to increase the acetylation of histones $\mathrm{H} 3$ and H4 (Supp. Fig. 4).

\subsection{Class I HDACs regulate Adam12 and Timp-1 expression}

With the use of semi-selective HDAC inhibitors we also sought to identify a particular class or HDAC isoform involved in TGF- $\beta$-induced Adam12 and Timp-1 expression. VPA inhibited Adam12 and Timp-1 expression at $1 \mathrm{mM}$ (Fig. 4A), a concentration at which it is proposed to be class I HDAC-specific (Gottlicher et al., 2001; Gurvich et al., 2004). MS-275 partially inhibited Adam 12 expression at $10 \mu \mathrm{M}$, again a concentration at which it is proposed to inhibit class I HDACs (Khan et al., 2008; Vannini et al., 2004), but did not inhibit TGF- $\beta$-induced Timp-1. Examination of TGF- $\beta$-induced ERK and Akt phosphorylation indicated that the concentrations at which the semi-selective HDAC inhibitors blocked Adam12 and Timp-1 expression paralleled those that inhibited ERK and Akt activation (Fig. 4B). To further demonstrate the role for class I HDACs we showed that apicidin, a class I specific HDAC inhibitor at concentrations of $10 \mu \mathrm{M}$ and below (Khan et al., 2008), also blocked the TGF- $\beta$ activation of ERK and Akt and significantly repressed both TGF- $\beta$-induced Adam 12 and Timp-1 expression (Fig. 4C). There was no repressive effect of these HDAC inhibitors on Pai-1 expression (Supp. Fig. 5).

\subsection{HDAC3 regulates TGF- $\beta$-induced gene expression}

Treatment with a range of semi-selective HDAC inhibitors suggested that a class I family HDAC was involved in TGF- $\beta$-induced gene expression. To further identify the HDACs involved we depleted each class I HDAC independently with siRNAs (Supp Fig. 6). Consistent with the effect of HDAC inhibitors, depletion of each class I HDAC revealed that HDAC3 was required for the TGF- $\beta$ induction of both Timp- 1 and 

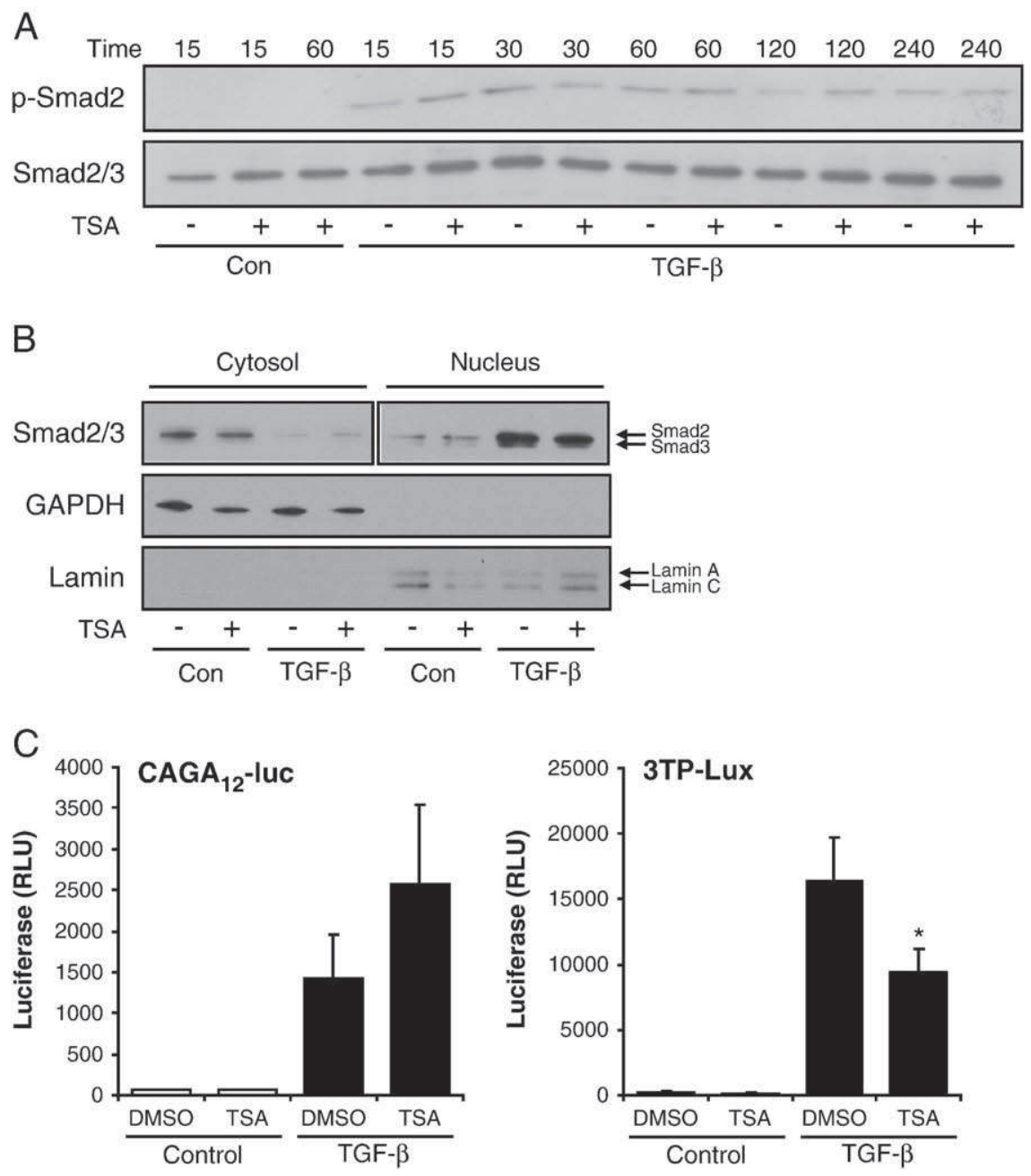

Fig. 2. HDAC inhibitors do not down-regulate Smad signalling. (A) Cells were stimulated with TGF- $\beta 1$ ( $2 \mathrm{ng} / \mathrm{ml})$ for the indicated times after treatment with TSA (100 ng/ml). Cell lysates were immunoblotted with Smad antibodies. (B) Cells were stimulated with TGF- $\beta 1(2 \mathrm{ng} / \mathrm{ml})$ for $1 \mathrm{~h}$ after treatment with TSA (100 ng/ml) or DMSO (0.01\% v/v) control. Nuclear and cytoplasmic extracts were prepared and immunoblotted with the indicated antibodies. (C) Cells were transfected with (i) CAGA 12 -luc or (ii) 3TP-Lux luciferase expression vectors for $24 \mathrm{~h}$, serum-starved for $16 \mathrm{~h}$, then stimulated with TGF- $31(2 \mathrm{ng} / \mathrm{ml})$ for $8 \mathrm{~h}$ after treatment with TSA (100 ng/ml) or DMSO (0.01\% v/v) control. Luciferase activity was quantified from cell lysates and is presented as mean \pm S.D. $\left({ }^{*} p<0.05\right)$. Data are representative of three independent experiments.

Adam12 (Fig. 5A). By contrast, depletion of HDAC3 had no effect on the induction of Pai-1 expression. To support this result we used an additional siRNA targeting a different region of the HDAC3 transcript, which elicited similar levels of HDAC3 depletion (Fig. 6B), and found that this also repressed TGF- $\beta$-induced Timp-1 and Adam12 (Fig. 5B).

\subsection{HDAC3 regulates TGF- $\beta$-induced non-Smad signalling}

Having shown that Adam12 and Timp-1 induction by TGF- $\beta$ was HDAC3-dependent, we hypothesised that HDAC3 was required for TGF- $\beta$-induced Adam12 and Timp-1 expression by regulating the activation of ERK and Akt. siRNA-mediated depletion of HDAC3 also inhibited the activation of ERK and Akt correlating with the effect on gene expression (Fig. 6A and B).

\subsection{HDAC3 regulates the TGF- $\beta$ induction of Activator Proteins}

We have previously demonstrated that the induction of Timp-1 expression by TGF- $\beta$ is dependent on the intermediate expression of immediate early response genes such as the AP- 1 transcription factors (Young et al., 2005). We have also found that the expression of a number of TGF- $\beta$-induced AP-1 proteins is repressed by TSA (Young et al., 2005 and Supp. Fig. 7). Therefore, we sought to determine whether the induction of AP-1 subunits by TGF- $\beta$ was also dependent on HDAC3.
Depletion of HDAC3 significantly reduced the induction of a number of AP-1 family members, including $c$-fos, fosb, c-jun, junb and fra-1/2 (Fig. 7).

\section{Discussion}

We have previously reported the repression of TGF- $\beta$-induced Timp-1 expression by HDAC inhibitors (Young et al., 2005). Here we sought to establish the mechanism by which HDAC inhibitors repress gene expression and the identity of the HDACs involved. By comparing Timp- 1 with two other TGF- $\beta$-inducible genes, Adam 12 and Pai-1, we confirmed that only a subset of genes are repressed by HDAC inhibitors. As the induction of Adam 12 and Timp-1 by TGF- $\beta$ is Smad-dependent we first studied the effect of TSA on Smad signalling. Our data examining the expression of the classically Smad-dependent gene, Pai-1, and the activation of Smad signalling, strongly suggest that HDAC inhibitors do not mediate their effects on a subset of TGF- $\beta$ responsive genes by modulation of the Smad pathway, consistent with the findings of Ghosh et al. (2007). In fact, at time-points beyond $1 \mathrm{~h}$ we found that TSA promoted Smad2, 3 and 4 nuclear accumulation (Supp. Fig. 8), which is consistent with the findings of Tu and Luo (2007). However, although $\mathrm{CAGA}_{12}$-luc and Pai-1 expression were not repressed we cannot completely exclude the possibility that acetylated nuclear Smad7 is interfering with Smad-DNA complex formation at our target genes (Zhang et al., 2007). 

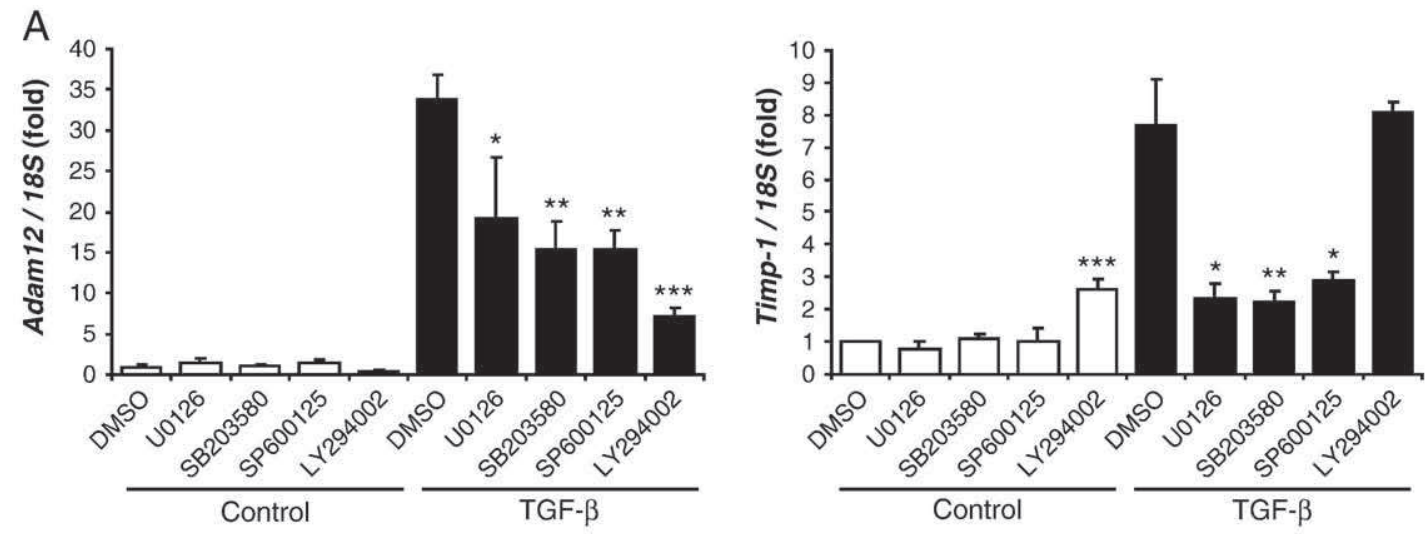

B

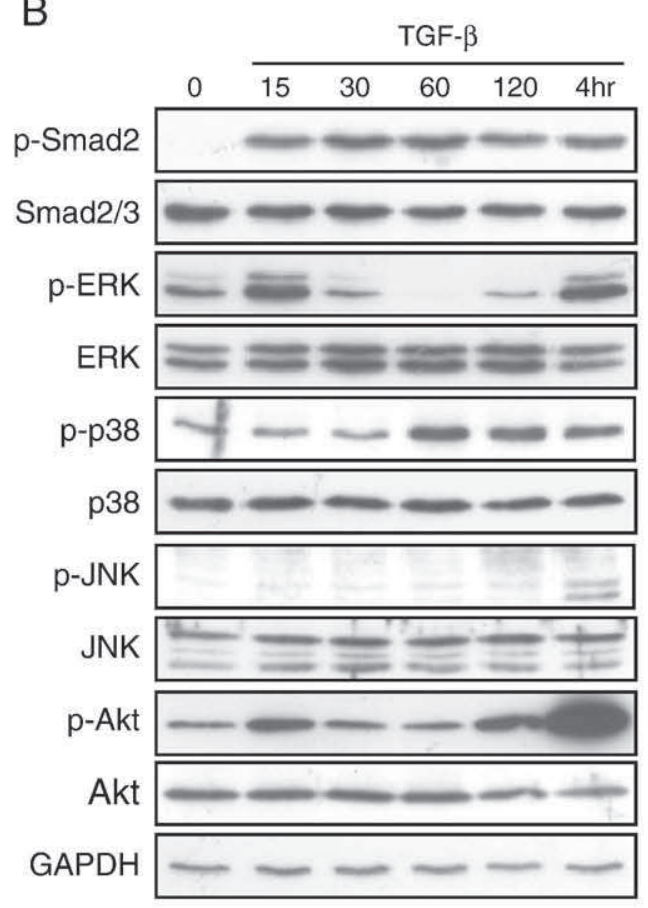

D

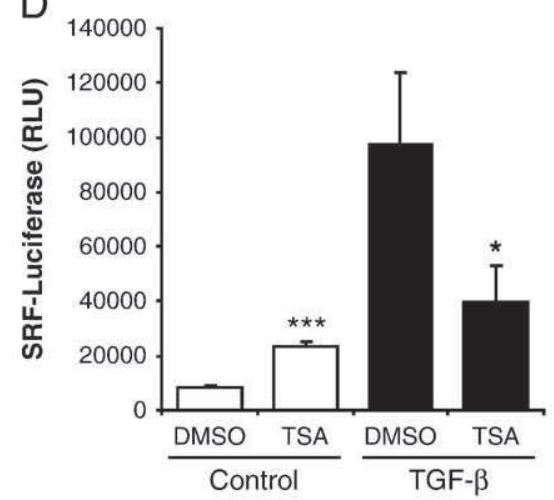

C

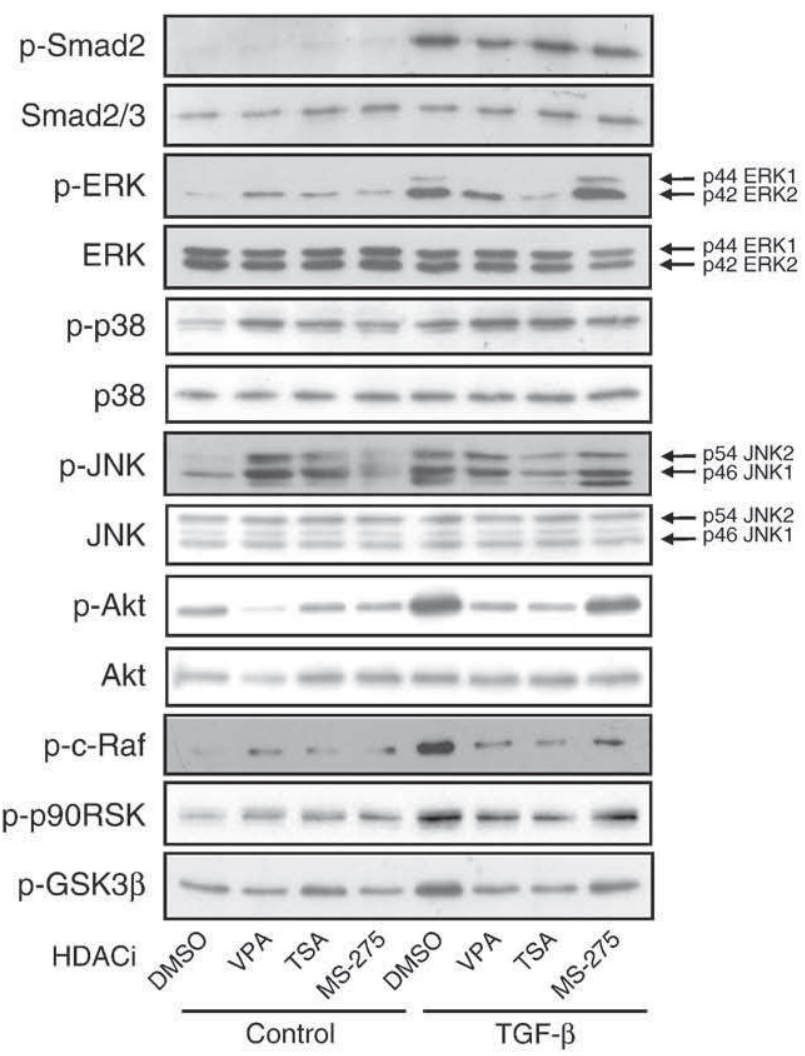

Fig. 3. HDAC inhibitors regulate the TGF- $\beta$ activation of signalling pathways. (A) Cells were stimulated with TGF- $\beta 1$ ( $2 \mathrm{ng} / \mathrm{ml})$ for $8 \mathrm{~h}$ after $30 \mathrm{minute}$ pre-treatment with MAPK selective inhibitors U0126 $(10 \mu \mathrm{M})$, SB203580 $(10 \mu \mathrm{M})$ or SP600125 (30 $\mu \mathrm{M})$, or PI3K inhibitor LY294002 $(10 \mu \mathrm{M})$, with DMSO control $(0.1 \% \mathrm{v} / \mathrm{v})$. RNA was isolated and gene expression quantified by real-time RT-PCR and normalised to the housekeeping gene $18 \mathrm{~S}$. Data are presented as fold induction relative to the basal expression and represent mean \pm S.D. ( $n=3$, ${ }^{*} p<0.05$, ${ }^{* *} p<0.01$,*** $\left.p<0.001\right)$. (B) Cells were stimulated with TGF- $\beta 1(2 \mathrm{ng} / \mathrm{ml})$ for the indicated times and cell lysates analysed by immunoblotting with the indicated antibodies. (C) Cells were stimulated with TGF- $\beta 1(2 \mathrm{ng} / \mathrm{ml})$ for $4 \mathrm{~h}$ after treatment with TSA $(100 \mathrm{ng} / \mathrm{ml})$, VPA $(10 \mathrm{mM})$, MS-275 $(1 \mu \mathrm{M})$ or DMSO $(0.01 \% \mathrm{v} / \mathrm{v})$. Cell lysates were immunoblotted with the indicated antibodies. (D) Cells were transfected with SRF luciferase expression vector for $24 \mathrm{~h}$, serum-starved for $16 \mathrm{~h}$, then stimulated with TGF- $\beta 1$ ( $2 \mathrm{ng} / \mathrm{ml}$ ) for $8 \mathrm{~h}$ after treatment with TSA $(100 \mathrm{ng} / \mathrm{ml})$ or DMSO $(0.01 \% \mathrm{v} / \mathrm{v})$ control. Luciferase activity was quantified from cell lysates and is presented as mean \pm S.D. $\left({ }^{*} p<0.05\right.$, $\left.{ }^{* * *} p<0.001\right)$. Data are representative of three independent experiments. 
A
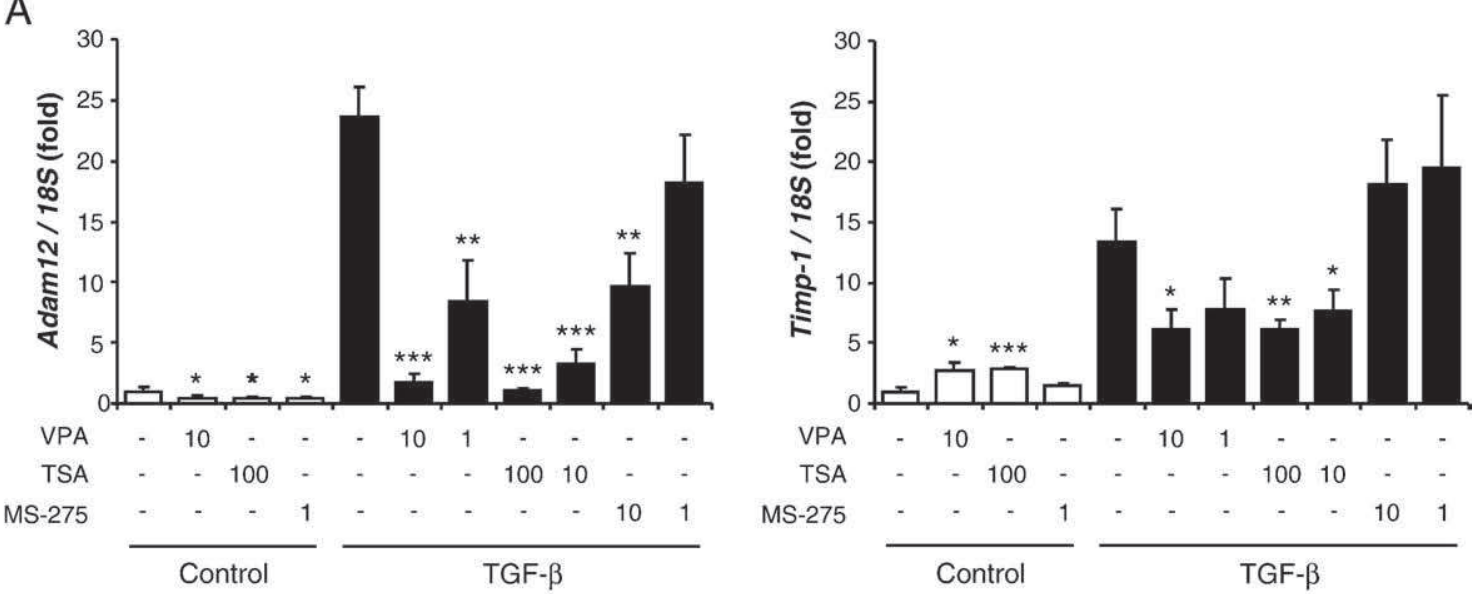

B
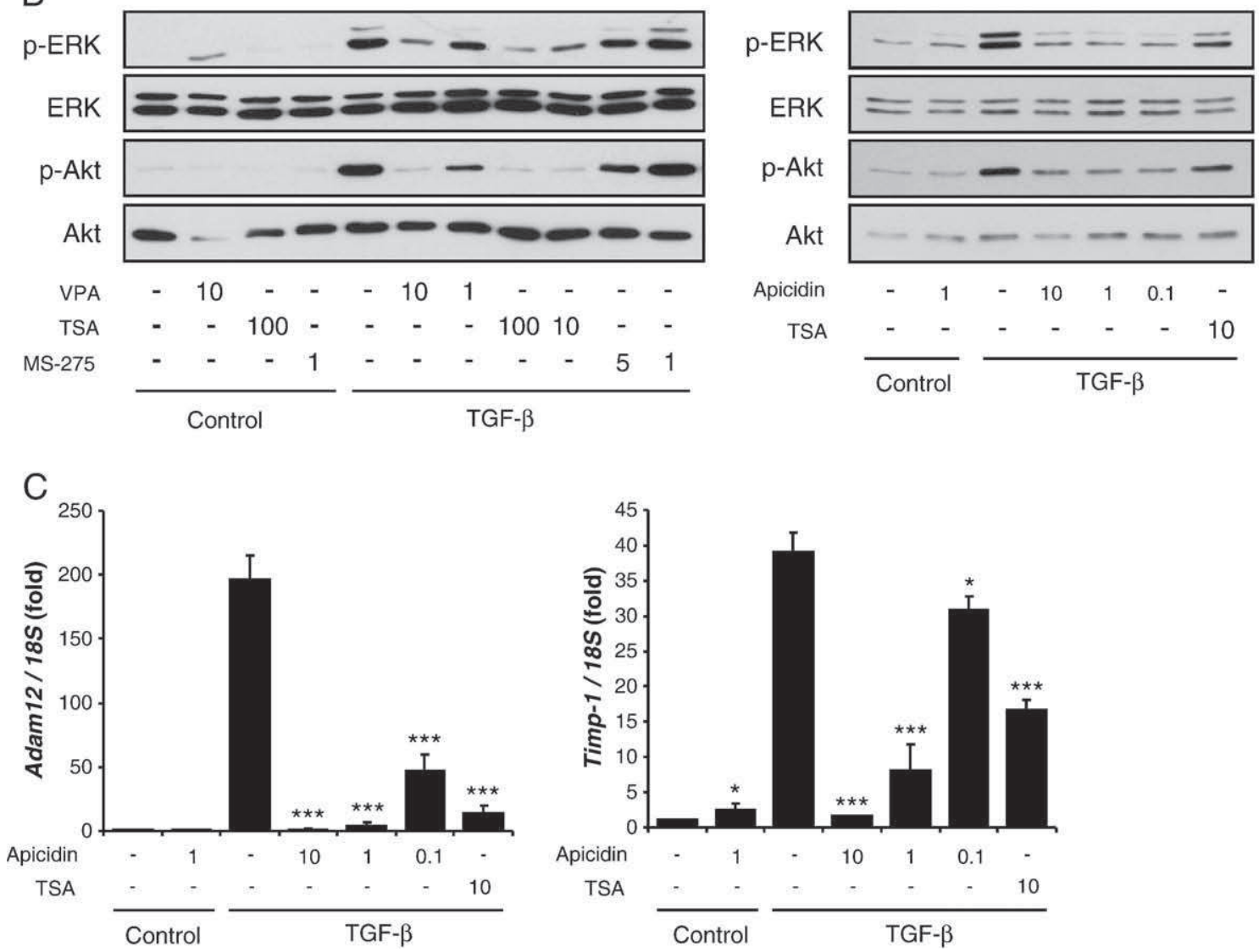

Fig. 4. HDAC inhibitors differentially effect TGF- $\beta$-induced gene expression. Cells were stimulated with TGF- $\beta 1$ ( $2 \mathrm{ng} / \mathrm{ml})$ for (A and C) $8 \mathrm{~h}$ or (B) $4 \mathrm{~h}$ after treatment with the indicated concentrations of HDAC inhibitors VPA $(\mathrm{mM})$, TSA $(\mathrm{ng} / \mathrm{ml})$, MS-275 $(\mu \mathrm{M})$, or apicidin $(\mu \mathrm{M})$, with DMSO $(0.01 \% \mathrm{v} / \mathrm{v})$ control. (A and C) Gene expression was measured by real-time RT-PCR and normalised to $18 \mathrm{~S}$. Data are presented as fold induction relative to the basal expression and represent mean \pm S.D. $\left(n=3\right.$, ${ }^{*} p<0.05$, $\left.{ }^{* *} p<0.01,{ }^{* * *} p<0.001\right)$. (B) Cell lysates were immunoblotted with the indicated antibodies. Data are representative of three independent experiments.

In addition to Smad signalling, TGF- $\beta$ activates a number of alternative signalling pathways. Indeed, we showed that in addition to Smad phosphorylation, TGF- $\beta$-activated MAPK and PI3K signalling with a range of kinetics; the transient activation being consistent with previous observations in C3H10T1/2 cells (Lien et al., 2006). Although we have conclusively shown that the TGF- $\beta$ induction of Adam 12 and Timp-1 expression is Smad-dependent, Adam12 induction has also been shown to require ERK and Akt signalling (Le Pabic et al., 2003, 2005), while Timp-1 induction is reportedly dependent on ERK activation (Kwak et al., 2006). We used pharmacological inhibitors to confirm that these signalling pathways are required, and also provide evidence that p38 and JNK signalling may also be involved, although concerns about the lack of specificity of the p38 and JNK inhibitors must be considered (Bain et al., 2007). The effect on basal Adam12 and Timp-1 expression may be due to the inhibitors preventing endogenous TGF- $\beta$-activated non-Smad signalling present between the cells in culture (Supp. Fig. 9). Taken together, these data indicate the significant role of non-Smad signalling in the subset of TGF- $\beta$-induced genes repressed by HDAC inhibitors.

HDAC inhibitors have been found to regulate cell signalling networks in transformed cells, although many of these studies use a minimum of 24 hour HDAC inhibitor treatment (Chen et al., 2005; 


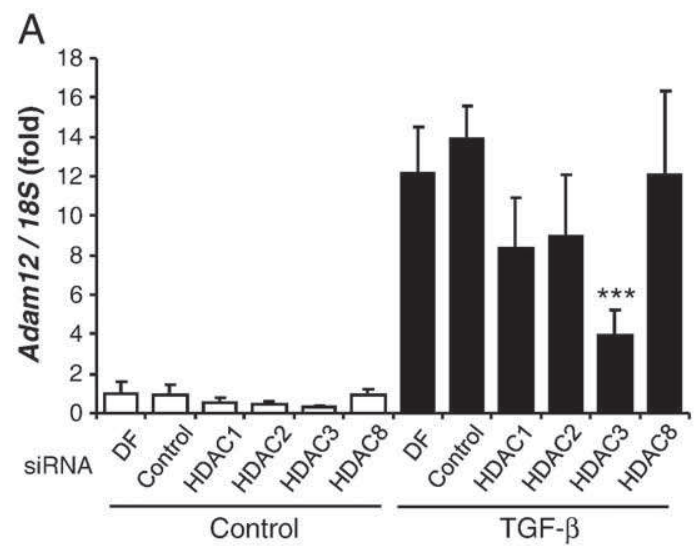

B
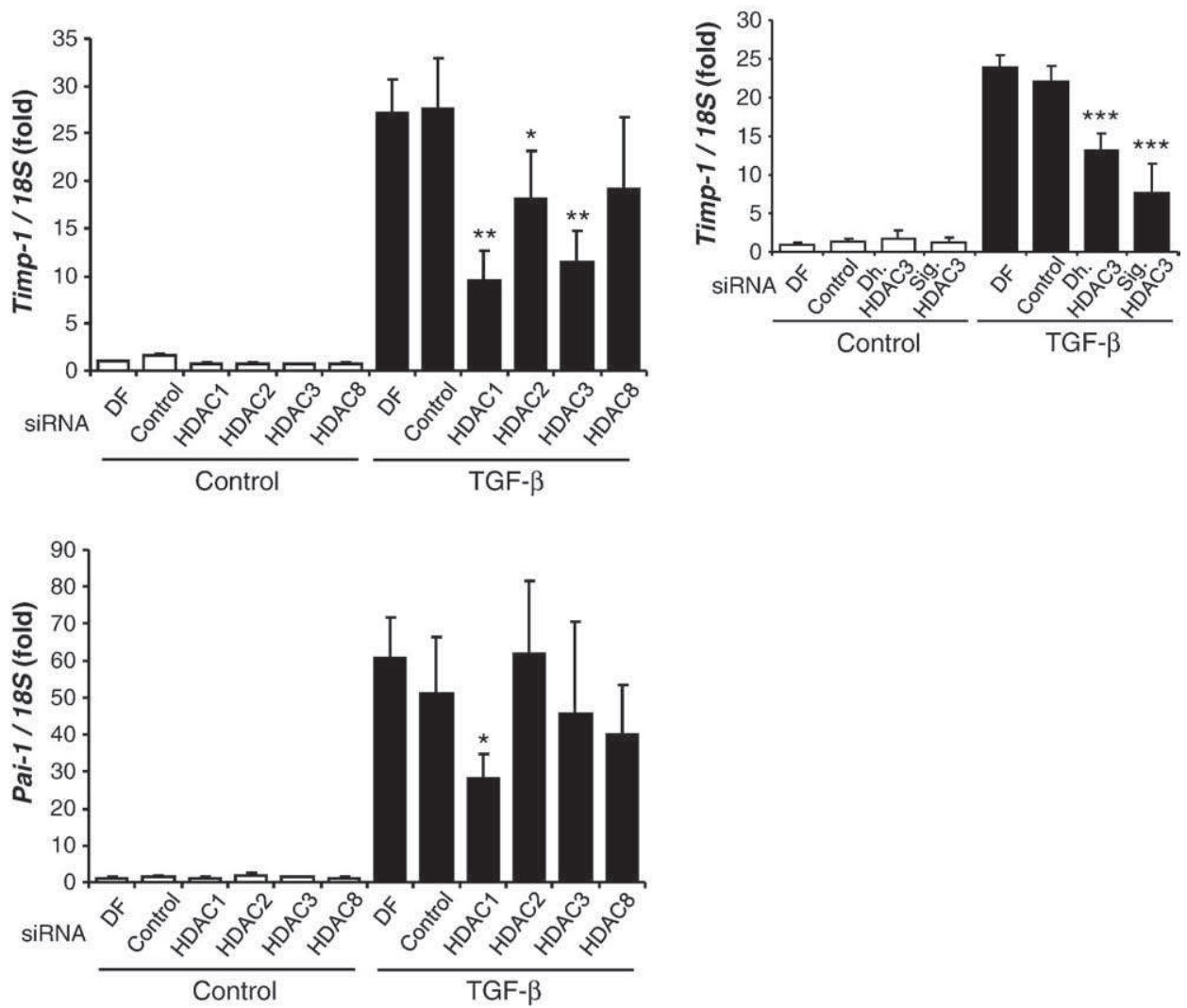

Fig. 5. HDAC3 regulates TGF- $\beta$-induced gene expression. (A) Cells were transfected with the indicated class I HDAC-targeting siRNAs, non-targeting control siRNA (25 nM), or mocktransfected with Dharmafect (DF) alone for $24 \mathrm{~h}$, serum-starved for $16 \mathrm{~h}$, then stimulated with TGF- $\beta 1$ ( $2 \mathrm{ng} / \mathrm{ml})$ for $8 \mathrm{~h}$. RNA was isolated and gene expression quantified by realtime RT-PCR and normalised to 18S. (B) Cells were transfected with the indicated HDAC3-targeting siRNAs (Dh, Dharmacon; Sig, Sigma), non-targeting control siRNA (25 nM) for $24 \mathrm{~h}$ or mock-transfected with Dharmafect (DF) alone, serum-starved for $16 \mathrm{~h}$, then stimulated with TGF- $\beta 1$ ( $2 \mathrm{ng} / \mathrm{ml}$ ) for $8 \mathrm{~h}$. Gene expression was quantified by real-time RT-PCR and normalised to $18 \mathrm{~S}$. Data are presented as fold induction relative to the basal expression and represent mean \pm S.D. $\left(n=4\right.$, ${ }^{*} p<0.05$, $\left.{ }^{* *} p<0.01,{ }^{* * *} p<0.001\right)$. Data are representative of at least three independent experiments.

Fecteau et al., 2002; Kobayashi et al., 2006; Yu et al., 2002). We demonstrated that HDAC inhibitors reduced the level of both TGF- 3 induced ERK and Akt phosphorylation, and to a lesser extent JNK phosphorylation. Importantly, our report is the first to demonstrate that HDACs can modulate a number of intracellular signalling cascades in response to growth factors. This appeared to be a TGF$\beta$-specific effect, because in the absence of the growth factor HDAC inhibitors activated MAPK signalling, as previously noted for VPA (Michaelis et al., 2006). Furthermore, when examining IL-1 activation of MAPK we found no repression by TSA, albeit in cultured human articular chondrocytes (Supp. Fig. 10). The ERK and PI3K/Akt pathways are required for the expression of a number of TGF- $\beta$-inducible genes, including collagen and smooth muscle actin which are also known to be suppressed by HDAC inhibitors (Glenisson et al., 2007;
Rombouts et al., 2002; Yoshikawa et al., 2007). The down-regulation of signalling pathways that we have identified would also cause the repression of these genes.

Significantly, the activity of HDAC inhibitors to suppress gene expression paralleled their respective potency in suppressing signalling. This finding suggests HDAC inhibitors suppress Adam 12 and Timp-1 expression by down-regulating signalling. Consequently, MS275 was unable to suppress gene expression at concentrations which had no effect on signalling. Furthermore, the more robust TGF- $\beta$ induced Pai-1 expression, potentially a result of its SBE-containing promoter, is unaffected by HDACi because its induction is not dependent on ERK and PI3K signalling (Supp. Fig. 11).

Semi-selective inhibition of class I HDACs and RNAi-mediated depletion of class I HDAC3 reduced expression of Adam12 and Timp-1 
A

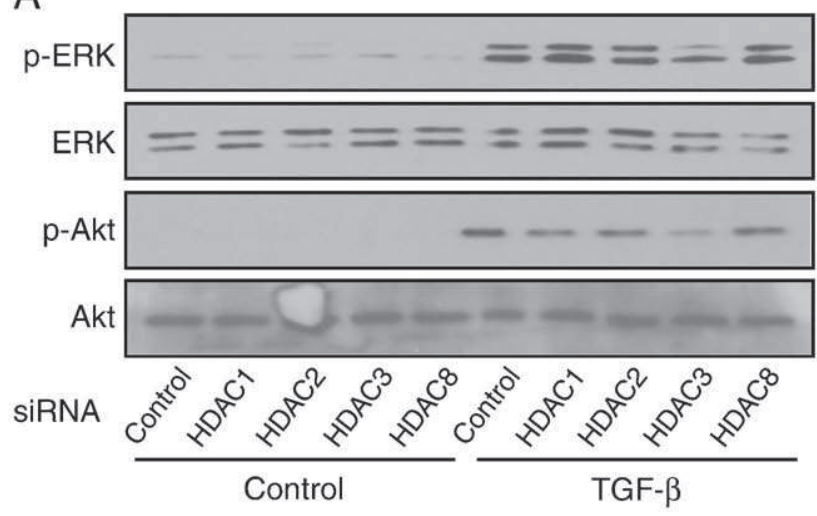

B

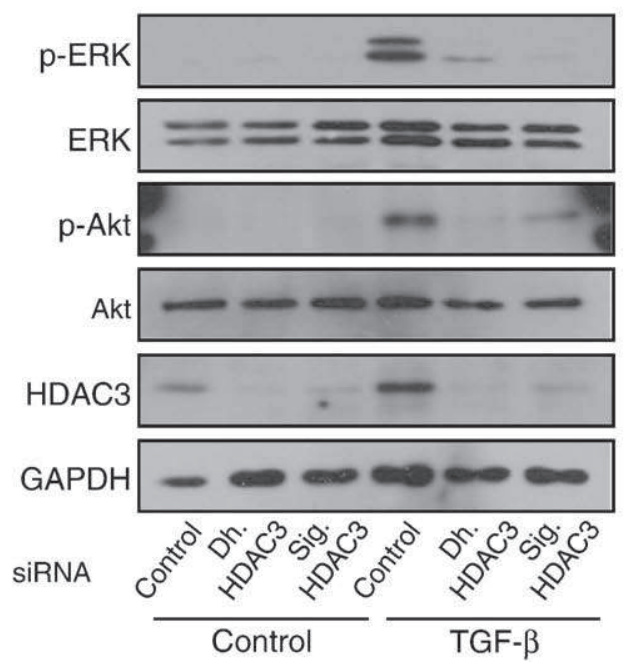

Fig. 6. HDAC3 regulates TGF- $\beta$-induced ERK and Akt activation. (A) Cells were transfected with the indicated class I HDAC-targeting siRNAs, non-targeting control siRNA ( $25 \mathrm{nM}$ ) for $24 \mathrm{~h}$, serum-starved for $16 \mathrm{~h}$, then stimulated with TGF- $\beta 1(2 \mathrm{ng} / \mathrm{ml})$ for $4 \mathrm{~h}$. Cell lysates were immunoblotted with the indicated antibodies. (B) Cells were transfected with the indicated HDAC3-targeting siRNAs (Dh, Dharmacon; Sig, Sigma) or non-targeting control siRNA ( $25 \mathrm{nM}$ ) for $24 \mathrm{~h}$, serum-starved for $16 \mathrm{~h}$, then stimulated with TGF- $\beta 1(2 \mathrm{ng} / \mathrm{ml})$ for $4 \mathrm{~h}$. Cell lysates were immunoblotted with the indicated antibodies. Data are representative of three independent experiments.

indicating that HDAC3 is critical to gene induction. Depletion of HDAC3, but not HDAC1 or HDAC2, also prevented the induction of the c-Jun gene by phorbol 12-myristate 13-acetate (PMA), causing the suppression of c-Jun target genes such as MMP-1, COX-2 and cyclin D1 (Yamaguchi et al., 2005). HDAC3 exists in different multi-subunit complexes to the other class I HDACs, including SMRT and N-CoR, which allows it to associate with class II HDACs 4, 5 and 7 (de Ruijter et al., 2003; Verdin et al., 2003). Therefore, it cannot be excluded that class II HDACs are also involved via their association with HDAC3. Indeed, Glenisson et al. (2007) reported that HDAC4 was required for TGF- $\beta$-induced $\alpha$-SMA expression by blocking the expression of the TG-interacting factors (TGIF) inhibitors of TGF- $\beta$ signalling. However, we also depleted the class II HDACs and found no effect of silencing HDAC4 on TGF- $\beta$-induced Adam 12 and Timp- 1 expression nor any evidence that HDAC inhibitors could induce TGIF expression in C3H10T1/2 cells, in fact TSA also blocked the induction of Tgif1 and Tgif2 by TGF- $\beta$ (Supp. Fig. 12). The effect of HDAC1 depletion on Pai-1 expression may be accounted for by deacetylase-independent functions of HDAC1 related to its presence in large multi-subunit complexes (de Ruijter et al., 2003; Verdin et al., 2003).

Further demonstrating the link between HDACs and TGF- $\beta$ induced ERK and Akt, we found that HDAC3 was also required for signalling pathway activation. This suggested for the first time that HDAC3 is required for efficient gene expression via its role in activating signalling pathways. Previously HDAC3 has only been recognised for its role in suppressing signalling pathways such as $\mathrm{p} 38$, NF-KB and JAK/STAT (Chen et al., 2001; Mahlknecht et al., 2004; Togi et al., 2009). We over-expressed active and deacetylase-inactive forms of HDAC3 in our C3H10T1/2 cells but found no significant effect on the induction of a proximal promoter Timp-1 construct (Supp. Fig. 13). This may be a consequence of the complex multi-subunit roles of HDAC3 masking an effect of HDAC3 over-expression or that the minimal promoter construct of Timp-1 does not contain the elements regulated by HDAC3.

The effects of inhibition or depletion of HDACs on the ERK and PI3K pathways may be due to enhanced phosphatase activity or reduced activation. HDACs may modulate intracellular signalling cascades through their interaction with protein phosphatases (PP). These complexes can be disrupted by HDAC inhibitors, releasing the PP to catalyse Akt dephosphorylation (Chen et al., 2005). We investigated this mechanism and also found that PP inhibitors could partially reverse the HDAC-mediated dephosphorylation of ERK and Akt (Supp. Fig. 14). Acetylation of signalling pathway proteins may account for the regulation of signalling by HDACs, however, there is no evidence of acetylation of any members of these kinase cascades. The acetylation of MAPK phosphatase- 1 has been demonstrated, promoting its association with and dephosphorylation of p38 (Cao et al., 2008), but no inhibition of p38 was found in the present study.

Alternatively, HDAC3 may be involved in the induction of a factor required for signalling pathway activation and gene expression. The late activation of ERK and Akt is very likely Smad and new protein translation dependent; for example, TGF- $\beta$ induces an autocrine growth factor or Snail to activate Akt in mesenchymal cells or epithelial cells, respectively (Cho et al., 2007; Horowitz et al., 2004). Indeed Smad4 depletion negated the activation of ERK (data not shown), but we were unable to confirm a requirement for new protein synthesis as translation inhibitors induced ERK phosphorylation. The induction of Timp- 1 by TGF- $\beta$ requires new protein synthesis including the need for AP-1 transcription factors such as c-Fos (Young et al., 2005). Adam12 also has a partial requirement for new protein synthesis (Supp. Fig. 15), although no factors have yet been identified. We previously showed that the TGF- $\beta$ induction of $c-f o s$ is also repressed by TSA (Young et al., 2005), and it is suggested that HDACdependent dynamic turnover of histone tail acetylation must occur at the $c$-fos promoter for efficient gene expression (Hazzalin and Mahadevan, 2005). We now show that induction of a number of AP-1 transcription factors by TGF- $\beta$ requires HDAC3. Interestingly, Hazzalin and Mahadevan (2005) demonstrate association of HDAC3 with the $c$-fos promoter, however, it is as yet unclear how HDACs and dynamic turnover of acetylation are required for gene expression.

In conclusion, we have shown that the TGF- $\beta$ induction of Adam 12 and Timp-1 requires both the Smad pathway and non-Smad signalling such as MAPK and PI3K. HDAC inhibitors do not alter the Smad pathway, but repress TGF- $\beta$-induced ERK and PI3K/Akt. HDAC3 is required for both efficient gene expression and activation of ERK and PI3K by TGF- $\beta$. These data provide further evidence of how the TGF- $\beta$ signalling pathway is regulated by HDACs and acetylation, and how a number of TGF- $\beta$-induced genes involved in the remodelling and regulation of the extracellular matrix are regulated by HDAC inhibition.

\section{Experimental procedures}

\subsection{Materials}

TGF- $\beta 1$ was obtained from R\&D Systems (Abingdon, UK). Primers, valproic acid (VPA), Bradford assay reagent and dimethyl sulphoxide (DMSO) were obtained from Sigma Aldrich (Poole, UK). Trichostatin A (TSA), HDAC inhibitor-1 (MS-275), U0126, SB203580, SP600125, LY294002, and the protease inhibitor cocktail were obtained from 


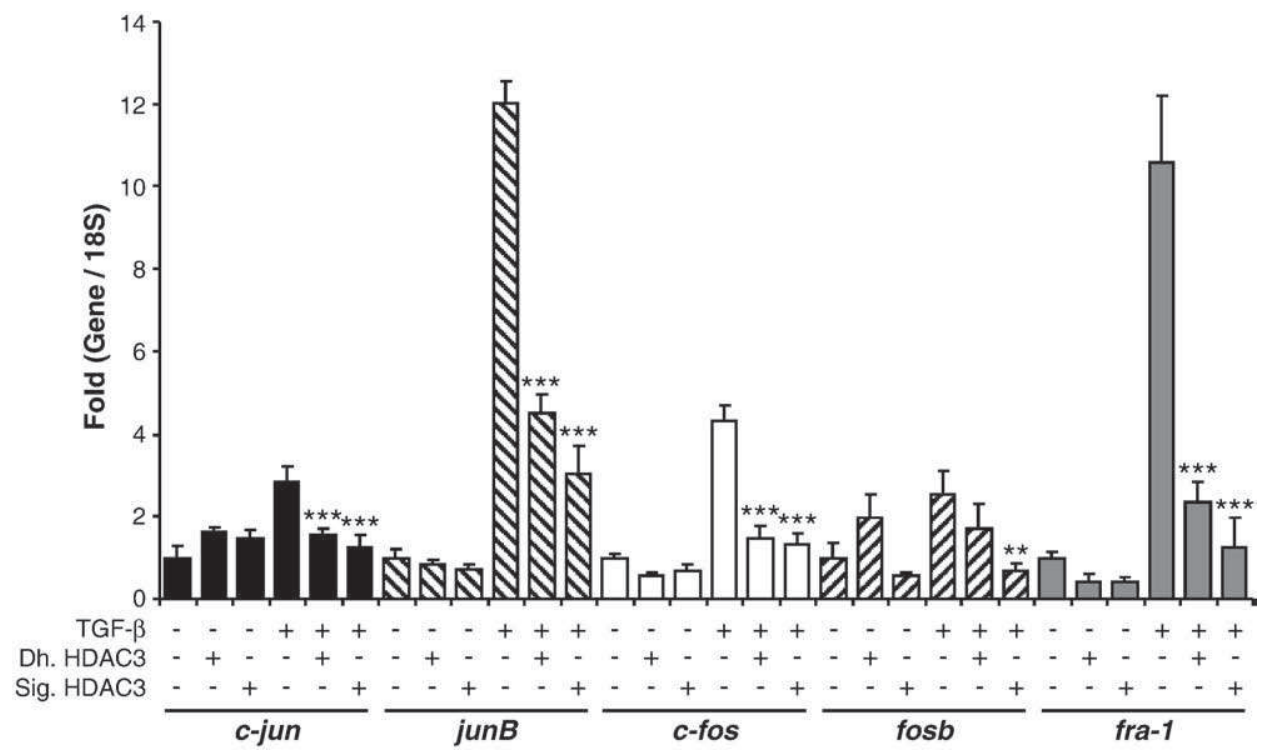

Fig. 7. HDAC3 regulates TGF- $\beta$-induced AP-1 expression. Cells were transfected with HDAC3-targeting siRNAs (Dh, Dharmacon; Sig, Sigma) or non-targeting control siRNA (25 nM) for $24 \mathrm{~h}$, serum-starved for $16 \mathrm{~h}$, then stimulated with TGF- $\beta 1(2 \mathrm{ng} / \mathrm{ml})$ for $3 \mathrm{~h}$. Gene expression was quantified by real-time RT-PCR and normalised to $18 \mathrm{~S}$. Data are presented as fold induction relative to the basal expression and represent mean \pm S.D. $\left(n=4,{ }^{* *} p<0.01,{ }^{* * *} p<0.001\right)$. Data are representative of three independent experiments.

Calbiochem (Nottingham, UK). Anti-mouse and rabbit secondary antibodies were obtained from DakoCytomation (Ely, UK). Cells-tocDNA II Kit was purchased from Ambion (Huntingdon, UK). Tissue culture reagents, Minimal Essential Medium (MEM) with Earle's salts and foetal calf serum (FCS) were obtained from Invitrogen (Paisley, UK). Reporter lysis buffer and luciferase assay reagent were from Promega (Southampton, UK).

\subsection{Cell culture}

Murine C3H10T1/2 fibroblasts were cultured in MEM with Earle's salts containing $10 \%$ FCS, L-glutamine $(2 \mathrm{mM}), 1 \%$ nonessential amino acids, $100 \mathrm{IU} / \mathrm{ml}$ penicillin and $100 \mu \mathrm{g} / \mathrm{ml}$ streptomycin essentially as previously described (Young et al., 2005). Monolayer cultures were maintained at $37^{\circ} \mathrm{C}$ in a $5 \%(\mathrm{v} / \mathrm{v}) \mathrm{CO}_{2}$ atmosphere. For all experiments, serum-free conditions used identical medium without FCS.

\section{3. $c D N A$ preparation and real-time $R T-P C R$ analysis}

C3H10T1/2 cells were plated overnight in 96-well plates at $80-90 \%$ confluence $\left(25,000\right.$ cells $\left./ \mathrm{cm}^{2}\right)$ in FCS-containing medium. The cells were then serum-starved overnight, followed by addition of TGF- $\beta$ and inhibitors at the indicated concentrations. After the indicated time period RNA was isolated via cell lysis, DNase I treated and cDNA was synthesised with Ambion Cells-to-cDNA II kit using MMLV reverse transcriptase and random hexamers following the manufacturer's instructions. TaqMan or SYBR Green real-time PCR was performed as described previously (Litherland et al., 2008). For TaqMan PCR, primer and probe sequences were: Adam12: For, 5'-ATCAGTGTCTTCGGCGTTCA-3' and Rev, 5'-GGCAATTCTTCCTGTTGTTACATACC-3', Probe: 5'-FAM-CCATGCAGTGCCACGGCCG-TAMRA-3'; Timp-1: For, 5'-CATGGAAAGCCTCTGTGGATATG-3' and Rev, 5'-AAGCTGCAGGCACTGATGTG3', Probe: 5'-FAM-CTCATCACGGGCCGCCTAAGGAAC-TAMRA-3'; Pai-1: For, 5'-CCGTCTCTGTGCCCATGAT-3' and Rev, 5'-GGCAGTTCCACGACGTCATA-3', Probe: 5'-FAM-CTCAGAGCAACAAGTTCAACTACACTGAGTTCACC-TAMRA-3'. For SYBR Green PCR, primer sequences were: Smad2: For, 5'-CTCTCCTGTTAATCACAGCTTGG-3' and Rev, 5'CAGAATGCAGGTTCCGAGTAA-3'; Smad3: For, 5'-TCCGTATGAGCTTCGTCAAA-3' and Rev, 5'-GGTGCTGGTCACTGTCTGTC-3'; Smad4: For, 5'CCGTGGGTGGAATAGCTC-3' and Rev, 5'-GGTCATCCACACCGATGC-3'; Hdac1: For, 5'-GGGCAGTGGTGCTAGGAG-3' and Rev, 5'-TTTTTCCCACG-
CAAATGG-3'; Hdac2: For, 5'-CTCCACGGGTGGTTCAGT-3' and Rev, 5'CCCAATTGACAGCCATATCA-3'; Hdac3: For, 5'-AGAGAGGTCCCGAGGAGAAC-3' and Rev, 5'-CGCCATCATAGAACTCATTGG-3'; Hdac8: For, 5'-GCAGCTGGCAACTCTGATT-3' and Rev, 5'-GTCAAGTATGTCCAGCAACGAG-3'; CyclophilinB: For, 5'-CTTCATAACCACAGTCAAGACCTC$3^{\prime}$ and Rev, 5'-CTCCACCTTCCGTACCACAT-3'; c-jun: For, 5'-CCAGAAGATGGTGTGGTGTTT-3' and Rev, 5'-CTGACCCTCTCCCCTTGC-3'; junB: For, 5'-CGTCTACACCAACCTCAGCA-3' and Rev, 5'-CGGGTATGAGCTCCCAGTC-3'; c-fos: For, 5'-CAGCCTTTCCTACTACCATTCC-3' and Rev, 5'-ACAGATCTGCGCAAAAGTCC-3'; fosB: For, 5'-GTTCGCAGAGAGCGGAAC-3' and Rev, 5'-GCCTTTTCCTCTTCAAGCTG-3'; fra-1: For, 5'-CCCAGTACAGTCCCCCTCA-3' and Rev, 5'TCCTCCTCTGGGCTGATCT-3'; For both methods, reactions were amplified in a 96-well optical reaction plate (Applied Biosystems) and quantified using an ABI $7900 \mathrm{HT}$ real-time PCR system and the manufacturer's corresponding software (Applied Biosystems). Relative quantity of mRNAs was calculated using the comparative cycle threshold method and normalised by 18S, Cyclophilin or Gapdh (Applied Biosystems) for the amount of RNA input.

\subsection{RNA-mediated interference}

For siRNA transfection 25 nM siRNA was transfected into $30-40 \%$ confluent C3H10T1/2 cells $\left(10,000\right.$ cells $\left./ \mathrm{cm}^{2}\right)$ using Dharmafect ${ }^{\mathrm{TM}} 1$ lipid reagent (Thermo Fisher). Dharmacon siRNA SMARTpools ${ }^{\circledR}$ (Thermo Fisher Scientific, Lafayette, Co.) of 4 specific siRNA duplexes (total of $25 \mathrm{nM}$ siRNA) were used to target Smad2 (NM_010754 [GenBank], cat: M_040707); Smad3 (NM_016769 [GenBank], cat: M_040706); Smad4 (NM_008540 [GenBank], cat: M_040687); HDAC1 (NM_008228 [GenBank], cat: M_040287); HDAC2 (NM_008229 [GenBank], cat: M_046158); HDAC3 (NM_010411 [GenBank], cat: M_043553); HDAC8 (NM_027382 [GenBank], cat: M_058613). Sigma MISSION® HDAC3 siRNA was also used to target HDAC3 (cat: SASI_Mm01_00162230). After a 24 hour transfection, cells were washed in serum-free medium for $16 \mathrm{~h}$ prior to the addition of TGF- $\beta 1(2 \mathrm{ng} / \mathrm{ml})$. Cells were then lysed for immunoblotting (below) or the RNA isolated and reverse transcribed for real-time RT-PCR. Depletion of gene-specific mRNA levels was calculated by comparison of expression levels with cells transfected with $25 \mathrm{nM}$ siCONTROL (non-targeting siRNA 2, cat. 001210-02; Dharmacon) and 25 nM AllStars Negative Control siRNA (cat: 1027280; Qiagen). 


\subsection{Immunoblotting}

C3H10T1/2 cells were plated overnight at a density of 25,000 cells/ $\mathrm{cm}^{2}$, serum-starved the following day for $16 \mathrm{~h}$ overnight then stimulated as indicated. Following treatment, cell extracts were prepared as described previously (Litherland et al., 2008). For extraction of histones, cell extracts were collected in triton extraction buffer (PBS containing 0.5\% Triton-X-100 (v/v), 2 mM PMSF, 0.02\% $(\mathrm{w} / \mathrm{v}) \mathrm{NaN}_{3}$ ). After centrifugation, the histones were isolated in $0.2 \mathrm{~N}$ $\mathrm{HCl}$ overnight. Lysates were resolved by SDS-PAGE, transferred to polyvinylidine difluoride (PVDF) membranes (Millipore, Watford, UK), and subsequently probed using the following antibodies: phospho-Smad2, phospho-ERK1/2, ERK1/2, phospho-p38, p38, phospho-JNK, JNK, phospho-Akt, Akt, acetyl-histone 3, acetyl-histone 4, histone 3, histone 4, phospho-c-Raf, phospho-MEK, phospho-GSK3 $\beta$, phospho-p90RSK, lamin A/C, Caspase-3, HDAC1, HDAC2, HDAC3 and HDAC8 from Cell Signaling Technology (Beverly, MA); Smad4 from Santa Cruz (CA, USA); Smad2/3 from Upstate (NY, USA); GAPDH from Chemicon (Southampton, UK); acetyl- $\alpha$-tubulin and $\alpha$-tubulin from Sigma Aldrich (Poole, UK).

\subsection{Plasmid, transient transfection and reporter gene assays}

Cells were seeded overnight in 24-well plates at a density of 10,000 cells $/ \mathrm{cm}^{2}$. Cells were then transfected for $24 \mathrm{~h}$ in serumcontaining medium with $0.2 \mu \mathrm{g}$ per well reporter plasmid using FuGene HD (Roche, Lewes, UK) according to the manufacturer's instructions. The following day, cells were washed in PBS, incubated in serum-free medium for $16 \mathrm{~h}$ and then stimulated with TGF- $\beta 1$ ( $2 \mathrm{ng} / \mathrm{ml}$ ). Cell extract was collected in reporter lysis buffer (Promega) and assayed with luciferase assay reagent (Promega) in a Microlumat PLUS luminometer (Berthold Technologies (U.K.) Ltd., Redbourn, UK).

\subsection{Statistical analyses}

Statistical differences between sample groups were assessed using the two-tailed Student's $t$-test, where ${ }^{*}, p<0.05$; $^{* *}, p<0.01$; and ${ }^{* * *}, p<$ 0.001 .

\section{Acknowledgements}

This work was supported by the Arthritis Research Campaign, the Dunhill Medical Trust, JGW Patterson Foundation, Fighting Arthritis in the North East and the Medical Research Council.

\section{Appendix A. Supplementary data}

Supplementary data associated with this article can be found, in the online version, at doi:10.1016/j.matbio.2010.05.002.

\section{References}

Bain, J., Plater, L., Elliott, M., Shpiro, N., Hastie, C.J., McLauchlan, H., Klevernic, I., Arthur, J.S., Alessi, D.R., Cohen, P., 2007. The selectivity of protein kinase inhibitors: a further update. Biochem. J. 408, 297-315.

Cao, W., Bao, C., Padalko, E., Lowenstein, C.J., 2008. Acetylation of mitogen-activated protein kinase phosphatase-1 inhibits Toll-like receptor signaling. J. Exp. Med. 205, 1491-1503.

Chen, L., Fischle, W., Verdin, E., Greene, W.C., 2001. Duration of nuclear NF-kappaB action regulated by reversible acetylation. Science 293, 1653-1657.

Chen, C.S., Weng, S.C., Tseng, P.H., Lin, H.P., Chen, C.S., 2005. Histone acetylationindependent effect of histone deacetylase inhibitors on Akt through the reshuffling of protein phosphatase 1 complexes. J. Biol. Chem. 280, 38879-38887.

Cho, H.J., Baek, K.E., Saika, S., Jeong, M.J., Yoo, J., 2007. Snail is required for transforming growth factor-beta-induced epithelial-mesenchymal transition by activating PI3 kinase/Akt signal pathway. Biochem. Biophys. Res. Commun. 353, 337-343.

Clayton, A.L., Hazzalin, C.A., Mahadevan, L.C., 2006. Enhanced histone acetylation and transcription: a dynamic perspective. Mol. Cell 23, 289-296. de Ruijter, A.J., van Gennip, A.H., Caron, H.N., Kemp, S., van Kuilenburg, A.B., 2003. Histone deacetylases (HDACs): characterization of the classical HDAC family. Biochem. J. 370, 737-749.

Denker, A.E., Nicoll, S.B., Tuan, R.S., 1995. Formation of cartilage-like spheroids by micromass cultures of murine $\mathrm{C} 3 \mathrm{H} 10 \mathrm{~T} 1 / 2$ cells upon treatment with transforming growth factor-beta 1 . Differentiation 59, 25-34.

Dennler, S., Itoh, S., Vivien, D., ten Dijke, P., Huet, S., Gauthier, J.M., 1998. Direct binding of Smad3 and Smad4 to critical TGF beta-inducible elements in the promoter of human plasminogen activator inhibitor-type 1 gene. Embo J. 17, 3091-3100.

Derynck, R., Zhang, Y.E., 2003. Smad-dependent and Smad-independent pathways in TGF-beta family signalling. Nature 425, 577-584.

Fecteau, K.A., Mei, J., Wang, H.C., 2002. Differential modulation of signaling pathways and apoptosis of ras-transformed 10T1/2 cells by the depsipeptide FR901228. J. Pharmacol. Exp. Ther. 300, 890-899.

Ghosh, A.K., Mori, Y., Dowling, E., Varga, J., 2007. Trichostatin A blocks TGF-betainduced collagen gene expression in skin fibroblasts: involvement of Sp1. Biochem. Biophys. Res. Commun. 354, 420-426.

Glenisson, W., Castronovo, V., Waltregny, D., 2007. Histone deacetylase 4 is required for TGFbeta1-induced myofibroblastic differentiation. Biochim. Biophys. Acta 1773, $1572-1582$.

Glozak, M.A., Sengupta, N., Zhang, X., Seto, E., 2005. Acetylation and deacetylation of non-histone proteins. Gene 363, 15-23.

Gottlicher, M., Minucci, S., Zhu, P., Kramer, O.H., Schimpf, A., Giavara, S., Sleeman, J.P., Lo Coco, F., Nervi, C., Pelicci, P.G., Heinzel, T., 2001. Valproic acid defines a novel class of HDAC inhibitors inducing differentiation of transformed cells. Embo J. 20, $6969-6978$

Gregoretti, I.V., Lee, Y.M., Goodson, H.V., 2004. Molecular evolution of the histone deacetylase family: functional implications of phylogenetic analysis. J. Mol. Biol. $338,17-31$.

Gurvich, N., Tsygankova, O.M., Meinkoth, J.L., Klein, P.S., 2004. Histone deacetylase is a target of valproic acid-mediated cellular differentiation. Cancer Res. 64, 1079-1086.

Hazzalin, C.A., Mahadevan, L.C., 2005. Dynamic acetylation of all lysine 4-methylated histone $\mathrm{H} 3$ in the mouse nucleus: analysis at c-fos and c-jun. PLoS Biol. 3, e393.

Horowitz, J.C., Lee, D.Y., Waghray, M., Keshamouni, V.G., Thomas, P.E., Zhang, H., Cui, Z., Thannickal, V.J., 2004. Activation of the pro-survival phosphatidylinositol 3-kinase/ AKT pathway by transforming growth factor-beta1 in mesenchymal cells is mediated by p38 MAPK-dependent induction of an autocrine growth factor. J. Biol. Chem. 279, 1359-1367.

Khan, N., Jeffers, M., Kumar, S., Hackett, C., Boldog, F., Khramtsov, N., Qian, X., Mills, E., Berghs, S.C., Carey, N., Finn, P.W., Collins, L.S., Tumber, A., Ritchie, J.W., Jensen, P.B., Lichenstein, H.S., Sehested, M., 2008. Determination of the class and isoform selectivity of small-molecule histone deacetylase inhibitors. Biochem J. 409, 581-589.

Kobayashi, Y., Ohtsuki, M., Murakami, T., Kobayashi, T., Sutheesophon, K., Kitayama, H., Kano, Y., Kusano, E., Nakagawa, H., Furukawa, Y., 2006. Histone deacetylase inhibitor FK228 suppresses the Ras-MAP kinase signaling pathway by upregulating Rap1 and induces apoptosis in malignant melanoma. Oncogene 25, 512-524.

Kouzarides, T., 2007. Chromatin modifications and their function. Cell 128, 693-705.

Kuang, P.P., Zhang, X.H., Rich, C.B., Foster, J.A., Subramanian, M., Goldstein, R.H., 2007. Activation of elastin transcription by transforming growth factor-beta in human lung fibroblasts. Am. J. Physiol. Lung Cell. Mol. Physiol. 292, L944-L952.

Kwak, H.J., Park, M.J., Cho, H., Park, C.M., Moon, S.I., Lee, H.C., Park I.C., Kim, M.S., Rhee, C.H Hong, S.I., 2006. Transforming growth factor-beta1 induces tissue inhibitor of metalloproteinase-1 expression via activation of extracellular signal-regulated kinase and Sp1 in human fibrosarcoma cells. Mol. Cancer Res. 4, 209-220.

Le Pabic, H., Bonnier, D., Wewer, U.M., Coutand, A., Musso, O., Baffet, G., Clement, B., Theret, N., 2003. ADAM12 in human liver cancers: TGF-beta-regulated expression in stellate cells is associated with matrix remodeling. Hepatology 37 , 1056-1066.

Le Pabic, H., L'Helgoualc'h, A., Coutant, A., Wewer, U.M., Baffet, G., Clement, B., Theret, N., 2005. Involvement of the serine/threonine p70S6 kinase in TGF-beta1-induced ADAM12 expression in cultured human hepatic stellate cells. J. Hepatol. 43, 1038-1044.

Lee, M.K., Pardoux, C., Hall, M.C., Lee, P.S., Warburton, D., Qing, J., Smith, S.M., Derynck, R., 2007. TGF-beta activates Erk MAP kinase signalling through direct phosphorylation of ShcA. Embo J. 26, 3957-3967.

Li, B., Carey, M., Workman, J.L., 2007. The role of chromatin during transcription. Cell 128, 707-719.

Lien, S.C., Usami, S., Chien, S., Chiu, J.J., 2006. Phosphatidylinositol 3-kinase/Akt pathway is involved in transforming growth factor-beta1-induced phenotypic modulation of $10 \mathrm{~T} 1 / 2$ cells to smooth muscle cells. Cell. Signal. 18, 1270-1278.

Litherland, G.J., Dixon, C., Lakey, R.L., Robson, T., Jones, D., Young, D.A., Cawston, T.E., Rowan, A.D., 2008. Synergistic collagenase expression and cartilage collagenolysis are phosphatidylinositol 3-kinase/Akt signaling-dependent. J. Biol. Chem. 283, 14221-14229.

Mahlknecht, U., Will, J., Varin, A., Hoelzer, D., Herbein, G., 2004. Histone deacetylase 3, a class I histone deacetylase, suppresses MAPK11-mediated activating transcription factor-2 activation and represses TNF gene expression. J. Immunol. 173, 3979-3990.

Michaelis, M., Suhan, T., Michaelis, U.R., Beek, K., Rothweiler, F., Tausch, L., Werz, O., Eikel, D., Zornig, M., Nau, H., Fleming, I., Doerr, H.W., Cinatl Jr., J., 2006. Valproic acid induces extracellular signal-regulated kinase $1 / 2$ activation and inhibits apoptosis in endothelial cells. Cell Death Differ. 13, 446-453.

Rombouts, K., Niki, T., Greenwel, P., Vandermonde, A., Wielant, A., Hellemans, K., De Bleser, P., Yoshida, M., Schuppan, D., Rojkind, M., Geerts, A., 2002. Trichostatin A, a 
histone deacetylase inhibitor, suppresses collagen synthesis and prevents TGF-beta (1)-induced fibrogenesis in skin fibroblasts. Exp. Cell Res. 278, 184-197.

Shi, Y., Massague, J., 2003. Mechanisms of TGF-beta signaling from cell membrane to the nucleus. Cell 113, 685-700.

Togi, S., Kamitani, S., Kawakami, S., Ikeda, O., Muromoto, R., Nanbo, A., Matsuda, T. 2009. HDAC3 influences phosphorylation of STAT3 at serine 727 by interacting with PP2A. Biochem. Biophys. Res. Commun. 379, 616-620.

Tu, A.W., Luo, K., 2007. Acetylation of Smad2 by the co-activator p300 regulates activin and transforming growth factor beta response. J. Biol. Chem. 282, 21187-21196.

Vannini, A Volpari, C, Filocamo, G, Casavola, E.C Brunetti, M, Renzoni, D. Chakravarty, P., Paolini, C., De Francesco, R., Gallinari, P., Steinkuhler, C., Di Marco, S., 2004. Crystal structure of a eukaryotic zinc-dependent histone deacetylase, human HDAC8, complexed with a hydroxamic acid inhibitor. Proc. Natl. Acad. Sci. U. S. A. 101, 15064-15069.

Verdin, E., Dequiedt, F., Kasler, H.G., 2003. Class II histone deacetylases: versatile regulators. Trends Genet. 19, 286-293.

Wang, E.A., Israel, D.I., Kelly, S., Luxenberg, D.P., 1993. Bone morphogenetic protein-2 causes commitment and differentiation in C3H10T1/2 and 3T3 cells. Growth Factors 9, 57-71.

Whitmarsh, A.J., Shore, P., Sharrocks, A.D., Davis, R.J., 1995. Integration of MAP kinase signal transduction pathways at the serum response element. Science 269, 403-407.
Wrana, J.L., Attisano, L., Carcamo, J., Zentella, A., Doody, J., Laiho, M., Wang, X.F. Massague, J., 1992. TGF beta signals through a heteromeric protein kinase receptor complex. Cell 71, 1003-1014.

Xu, W.S., Parmigiani, R.B., Marks, P.A., 2007. Histone deacetylase inhibitors: molecular mechanisms of action. Oncogene 26, 5541-5552.

Yamaguchi, K., Lantowski, A., Dannenberg, A.J., Subbaramaiah, K., 2005. Histone deacetylase inhibitors suppress the induction of c-Jun and its target genes including COX-2. J. Biol. Chem. 280, 32569-32577.

Yoshikawa, M., Hishikawa, K., Marumo, T., Fujita, T., 2007. Inhibition of histone deacetylase activity suppresses epithelial-to-mesenchymal transition induced by TGF-beta1 in human renal epithelial cells. J. Am. Soc. Nephrol. 18, 58-65.

Young, D.A., Billingham, O., Sampieri, C.L., Edwards, D.R., Clark, I.M., 2005. Differential effects of histone deacetylase inhibitors on phorbol ester- and TGF-beta1 induced murine tissue inhibitor of metalloproteinases-1 gene expression. Febs J. 272, $1912-1926$.

Yu, X., Guo, Z.S., Marcu, M.G., Neckers, L., Nguyen, D.M., Chen, G.A., Schrump, D.S., 2002. Modulation of p53, ErbB1, ErbB2, and Raf-1 expression in lung cancer cells by depsipeptide FR901228. J. Natl. Cancer Inst. 94, 504-513.

Zhang, S., Fei, T., Zhang, L., Zhang, R., Chen, F., Ning, Y., Han, Y., Feng, X.H., Meng, A Chen, Y.G., 2007. Smad7 antagonizes transforming growth factor beta signaling in the nucleus by interfering with functional Smad-DNA complex formation. Mol. Cell. Biol. 27, 4488-4499. 